\title{
Ara Norenzayan, Big Gods. How Religion Transformed Cooperation And Conflict
}

Princeton and Oxford, Princeton University Press, 2014, 264 p.

Jean-Louis Ormières

\section{(2) OpenEdition}

\section{Journals}

Édition électronique

URL : http://journals.openedition.org/assr/26518

DOI : $10.4000 /$ assr.26518

ISSN : $1777-5825$

Éditeur

Éditions de l'EHESS

Édition imprimée

Date de publication : 31 décembre 2014

Pagination : 261

ISBN : 978-2-7132-2467-6

ISSN : 0335-5985

\section{Référence électronique}

Jean-Louis Ormières, « Ara Norenzayan, Big Gods. How Religion Transformed Cooperation And

Conflict », Archives de sciences sociales des religions [En ligne], 168 | 2014, mis en ligne le 18 mai 2015, consulté le 22 septembre 2020. URL : http://journals.openedition.org/assr/26518 ; DOI : https:// doi.org/10.4000/assr.26518

Ce document a été généré automatiquement le 22 septembre 2020.

(C) Archives de sciences sociales des religions 


\section{Ara Norenzayan, Big Gods. How Religion Transformed Cooperation And Conflict}

Princeton and Oxford, Princeton University Press, 2014, 264 p.

Jean-Louis Ormières

\section{RÉFÉRENCE}

Ara Norenzayan, Big Gods. How Religion Transformed Cooperation And Conflict, Princeton and Oxford, Princeton University Press, 2014, 264 p. 
Ce livre s'interroge et tente de rendre compte du succès des religions "monothéistes", majoritaires dans le monde depuis plusieurs siècles. L'entraide et l'altruisme, que prônent et sur lesquels s'appuient les fondateurs et les fidèles adeptes de ces "Grands Dieux » seraient, selon Ara Norenzayan, qui se réfère ici à de nombreuses études de psychologie sociale, à l'origine de cette réussite. Plusieurs de ces études reproduites pour la plupart en laboratoire témoignent en effet d'un lien réel entre générosité et niveau de religiosité. Mais il reconnaît que d'autres études l'infirment.

L'auteur, tout en se refusant à donner une définition précise de ce qu'il entend par "religion", et c'est bien là toute l'originalité et tout l'intérêt de sa démarche, considère que l'émergence et l'enracinement de ces «religions monothéistes» qui se singularisent par leur caractère «prosocial » ne peuvent se comprendre sans la coexistence et l'interrelation en leur sein de huit principes : 1) Tout un chacun est bienveillant ; 2) La religion est plus dans la situation que dans la personne ; 3) L'enfer est plus fort que le paradis ; 4) Faire confiance à ceux qui croient en Dieu; 5) Les actions religieuses sont plus éloquentes que les mots; 6) Seuls les dieux adorés sont des dieux omnipotents ; 7) Les Grands Dieux prospèrent au sein des grands groupes humains ; 8) La coopération interne permet à ces religions de mieux affronter la « concurrence ». Chacun de ces huit principes fait ici l'objet d'un chapitre qu'il serait trop long de résumer. Retenons que ces principes permettent de distinguer les religions monothéistes des religions polythéistes et le progrès des unes aux dépens des autres.

3 Les deux derniers chapitres traitent, l'un, de la relation entre religion et intolérance et des conflits inter-religieux, l'autre de l'athéisme et de la coopération au sein des sociétés sécularisées contemporaines.

4 La vision évolutionniste qui préside à la démarche d'Ara Norenzayan est à plus d'un titre problématique. Résumons la thèse de l'auteur: les petites communautés de nomades (chasseurs-cueilleurs) adoptèrent des systèmes religieux fondés sur le polythéisme; à partir de l'holocène, les groupes humains, devenus sédentaires, progressant en taille, abandonnent peu à peu le polythéisme au profit des "grands dieux ». Si l'on peut admettre que le polythéisme des sociétés de chasseurs-collecteurs s'est effacé au bénéfice du monothéisme dans les sociétés à " grands groupes ", tels que ceux de la plupart des sociétés contemporaines, on ne peut ignorer que nombre de sociétés autrefois constituées autour d'un état puissant contrôlant de vastes populations était demeuré " polythéiste ». Outre la Grèce antique et l'Empire romain (avant Constantin), citons également les Empires et royaumes africains du Moyen Âge, en particulier le Monomotapa ou l'Empire du Kongo. Outre le fait que l'auteur range 
l'hindouisme parmi les religions «monothéistes » ce qui est pour le moins discutable, faut-il par ailleurs admettre son point de vue selon lequel l'altruisme ne s'épanouirait qu'avec l'avènement et l'expansion de ces « Big Gods » ?

5 Autre lien contestable, celui que le psychologue établit, en citant notamment l'exemple des Mormons, entre le succès culturel et la vigueur des groupes sociaux religieux d'une part, et leur forte fécondité d'autre part. Nombre de pays sécularisés (Allemagne, Italie, Espagne), il est vrai, se caractérisent par une fécondité qui est désormais très inférieure au seuil de renouvellement des générations. Là encore, c'est néanmoins ne pas prendre en compte la forte baisse de la fécondité de la plupart des pays musulmans (la fécondité des femmes iraniennes est aujourd'hui inférieure à celle de la France et équivalente à celle du Royaume-Uni) qui ne s'accompagne pas pour autant d'un réel progrès de la sécularisation.

6 Mais surtout, l'idée que la croyance religieuse, et notamment celle qui a trait à l'adoration d'un seul Dieu, fait de l'être humain, une meilleure personne, que cette personne est d'autant plus animée de compassion et de moralité que ses faits et gestes sont observés par un Dieu omnipotent et omniscient est quelque peu excessive. Les statistiques internationales sur certains indices de moralité, la criminalité par exemple, ne plaident pas en faveur de cette idée. Des enquêtes menées dans plusieurs pays, il ressort que l'affirmation selon laquelle il est nécessaire de croire en Dieu pour être une personne morale est surtout présente dans les pays les plus pauvres, en Afrique et en Asie. Dès le xvII ${ }^{e}$ siècle, le philosophe Pierre Bayle affirmait dans ses «Pensées sur l'athéisme » que la problématique de la morale était indépendante de la religion et que les athées pouvaient avoir autant de sens moral que les chrétiens.

7 Certes les régimes totalitaires (communiste et fasciste) ont banni de leur système et combattu les religions, mais peut-on pour autant les considérer comme des régimes athées? Plusieurs auteurs ayant étudié ces régimes ont en effet montré qu'il s'agissait moins d'athéisme que de religions séculières.

8 L'Europe sécularisée, celle des pays scandinaves tout particulièrement, que l'auteur présente avec beaucoup de précautions comme un possible stade ultime de l'évolution de l'humanité, montre que des sociétés profondément sécularisées, voire athées, sont tout autant solidaires, pacifiées et pénétrées de bonnes mœurs que celles dont les populations demeurent très attachées à leur « GrandDieu ».

9 Dans cette Europe sécularisée où la diminution des préjugés à l'encontre des athées a autorisé leur progression, des institutions étatiques fortes, un système judiciaire et la primauté du droit ont permis d'assurer une coopération et une solidarité tout aussi efficace que là où subsiste un pouvoir surnaturel. Ces institutions ont peu à peu précipité le déclin de la religion en usurpant ses fonctions de solidarité et de consolidation de la communauté. En somme un Big Brother «cool» s'est ici substitué aux Big Gods qui prédominent encore dans une grande partie du reste du monde !

10 En dépit des critiques que peuvent susciter certains de ses aspects, une telle démarche évolutionniste n'en demeure pas moins profondément stimulante et originale. 